Valéria Metroski de Alvarenga ${ }^{1}$

\title{
Tendências da formação dos professores universitários que atuam nos cursos de artes visuais (Brasil e Argentina)
}

Trends in the training of university teachers who work in our visual arts courses (Brazil and Argentina)

Tendencias en la formación de profesores universitarios que trabajan en cursos de artes visuales (Brasil y Argentina) 


\section{Resumo}

No presente artigo, apresentaremos as tendências da formação inicial (Graduação) e continuada (Pós-Graduação stricto sensu) dos professores universitários (formadores) que atuam nos cursos de Graduação em Artes Visuais no Brasil e na Argentina. A pesquisa é resultante da tese de doutorado da autora, defendida em 2020 no PPGAV/UDESC. Os docentes selecionados são oriundos de 23 Instituições de Ensino Superior (IES) públicas que ofertam cursos de Graduação em Artes Visuais na modalidade presencial (10 na Argentina e 13 no Brasil), constituindo ao todo 604 profissionais (324 na Argentina e 280 no Brasil). Constatamos aspectos consonantes e dissonantes quanto às tendências de formação e exigências para atuação no Ensino Superior nos dois países. As semelhanças consistem nas áreas de formação inicial e continuada, assim como de produção artística ou não de acordo com os três eixos disciplinares (artístico/ateliê, teórico/histórico e pedagógico/ensino) de atuação dos docentes, e as diferenças estão mais voltadas para a titulação máxima e as legislações que regulamentam a profissão docente no Ensino Superior em ambos os países.

Palavras-chave: Artes Visuais. Professor universitário. Formação do formador. Brasil e Argentina. OFPEA/BRARG.

\section{Abstract}

In this article, we present the trends in initial (Graduate) and continuing (Post-Graduation stricto sensu) training of university professors (trainers) who work in Undergraduate courses in Visual Arts in Brazil and Argentina. The research is the result of the author's doctoral thesis, defended in 2020 at the PPGAV/ UDESC. The selected professors come from 23 public Higher Education Institutions (HEls) that offer undergraduate courses in Visual Arts in the on-site modality (10 in Argentina and 13 in Brazil), making up a total of 604 professionals (324 in Argentina and 280 in Brazil). We found consonant and dissonant aspects regarding training trends and requirements for Higher Education in both countries. The similarities consist of the areas of initial and continuing education, as well as artistic production or not according to the three disciplinary axes (artistic/studio, theoretical/historical and pedagogical/teaching) of the teachers' performance, and the maximum degree and the laws that regulate the teaching profession in higher education in both countries.

Keywords: Visual arts. College professor. Trainer training. Brazil and Argentina. OFPEA/BRARG.

1 Doutora e Mestra em Artes Visuais (UDESC), licenciada em Artes Visuais pela UFPR. Atua como professora de Arte na SEED/PR e como professora colaboradora na licenciatura em Artes Visuais da UEPG. Link do lattes: http://lattes.cnpq. br/2380674209566505. Link do ORCID: https://orcid.org/0000-0002-8975-5527. E-mail: valeriametroski@hotmail.com. 


\section{Resumen}

En este artículo, presentamos las tendencias en la formación inicial (Posgrado) y continua (Posgrado stricto sensu) de los profesores universitarios (formadores) que se desempeñan en los cursos de Grado en Artes Visuales en Brasil y Argentina. La investigación es fruto de la tesis doctoral del autor, defendida en 2020 en el PPGAV/UDESC. Los profesores seleccionados provienen de 23 Instituciones de Educación Superior (IES) públicas que ofrecen cursos de pregrado en Artes Visuales en la modalidad presencial (10 en Argentina y 13 en Brasil), sumando un total de 604 profesionales (324 en Argentina y 280 en Brasil). Encontramos aspectos consonantes y disonantes en cuanto a tendencias y requisitos formativos para la Educación Superior en ambos países. Las similitudes consisten en las áreas de formación inicial y continua, así como de producción artística o no según los tres ejes disciplinares (artístico/estudio, teórico/histórico y pedagógico/docente) de la actuación docente, y la titulación máxima y la leyes que regulan la profesión docente en la educación superior en ambos países.

Palabras clave: Artes Visuales. Profesor universitario. Formación de formadores. Brasil y Argentina. OFPEA / BRASIL 


\section{Introdução}

O principal objetivo deste artigo é apresentar as tendências da formação dos professores universitários que atuam nos cursos de Graduação em Artes Visuais por meio da identificação das áreas e habilitações da formação inicial e continuada, da titulação máxima e das condições de trabalho dos docentes em dois países: Brasil e Argentina.

Para cumprirmos tal objetivo, apresentaremos parte dos resultados da tese de doutorado da autora, intitulada "A formação dos professores formadores nos cursos de graduação em Artes Visuais: estudos comparados entre Brasil e Argentina", defendida em 2020 no Programa de Pós-Graduação (PPGs) em Artes Visuais da Universidade do Estado de Santa Catarina, sob orientação da professora doutora Maria Cristina da Rosa Fonseca da Silva.

A tese fez parte do projeto em rede "Observatório da Formação de Professores no âmbito do Ensino de Arte: estudos comparados entre Brasil e Argentina" (OFPEA/ BRARG), que foi criado em 2011 com os objetivos iniciais de averiguar elementos diversos da formação dos professores de Arte, mais especificamente de Artes Visuais, comparar cursos de Graduação e Pós-Graduação da área artística nos dois países, elaborar material bibliográfico para contribuir com os pesquisadores da área, assim como fortalecer as parcerias entre IES nacionais e internacionais (FONSECA DA SILVA; BÚJAN, 2016).

Há poucas pesquisas sobre a formação dos professores formadores na América Latina como um todo, independentemente das áreas do conhecimento (GATTI et al., 2019; VAILLANT, 2010), e quanto aos professores universitários da área de Arte, Rizzi (2013) e Teuber (2016) afirmam que as pesquisas são quase inexistentes. Em geral, o foco maior das investigações se encontra na formação docente para a Educação Básica. Nesse sentido, justifica-se esta pesquisa como uma forma de conhecer as tendências de formação, as condições de trabalho e as exigências para atuação dos professores universitários em Artes Visuais no Brasil e na Argentina, visando fornecer subsídios para outras investigações da área artística, assim como possíveis revisões de algumas políticas públicas educacionais no Ensino Superior.

Para encontrarmos as possíveis tendências da formação inicial e continuada, assim como a existência ou não de produção artística dos professores universitários que atuavam nos cursos de Graduação em Artes Visuais, analisamos os currículos de 604 profissionais, sendo 324 na Argentina e 280 no Brasil, oriundos de 23 IES públicas que ofertavam o curso de formação docente na modalidade presencial nessa linguagem artística (10 na Argentina e 13 no Brasil).

Buscamos utilizar o método de Marx para a pesquisa, que traz dois momentos indissociáveis: a investigação (ou a pesquisa) e a exposição (ou a apresentação): 
seus pormenores e suas conexões internas. Já a segunda é uma exposição crítica do objeto, de modo sistemático, com base em suas contradições, ou seja, uma exposição crítico-objetiva da lógica interna do objeto (seu movimento real). (CHAGAS, 2011; NETTO, 2011 apud ALVARENGA, 2020, p. 35).

No que se refere ao aporte teórico, valemo-nos de autores que dialogam com a perspectiva do materialismo histórico-dialético e da pedagogia histórico-crítica, tais como: Alvarenga (2020, 2021), Fonseca da Silva e Bújan (2016), Gatti et al. (2019), Lamarra e Centeno (2011), Souza e Paiva (2018), Vaillant (2010), entre outros. Além desses autores, foi necessário utilizarmos os sites do governo argentino (Ministerio de Ciencia, Tecnología e Innovación Productiva - Mincyt e Comisión Nacional de Evaluación y Acreditación Universitária - Coneau) e do governo brasileiro (Coordenação de Aperfeiçoamento de Pessoal de Nível Superior - Capes, Instituto Nacional de Estudos e Pesquisas Educacionais Anísio Teixeira - INEP e Ministério da Educação - MEC), assim como os sites das IES, para a coleta de dados sobre os cursos e sobre os professores.

Organizamos o artigo da seguinte forma: (1) Formação dos professores universitários (formadores); (2) Condições de trabalho, titulação máxima e exigências para atuação no Ensino Superior; (3) Universo da pesquisa: IES e professores universitários de Artes Visuais; (4) Tendências da formação dos professores formadores que atuam nos cursos de Artes Visuais (Brasil e Argentina) e, na sequência, temos as considerações finais e as referências.

\section{Formação dos professores universitários (formadores)}

A formação de professores para atuar na Educação Básica ocorre em cursos de Graduação (Licenciatura no Brasil e Professorado² na Argentina), que têm em seu currículo uma parte específica da área do conhecimento e uma parte pedagógica, e são devidamente reconhecidos por instituições competentes.

[...] na Argentina o termo bachiller (Bacharelado) corresponde a uma formação adquirida na educação secundária (equivalente ao Ensino Médio no Brasil). O título de Graduação denominado "Licenciatura", na Argentina equivale ao "Bacharelado" no Brasil. Neste país, os cursos de formação docente são denominados "Licenciatura", e na Argentina esses cursos são denominados "Professorados". (ALVARENGA, 2020, p. 48).

2 Ao longo do texto, quando usarmos o termo "Bacharelado", para os cursos na Argentina, ele corresponderá à formação do artista, e "Licenciatura" para nos referirmos aos cursos de formação docente, tanto no Brasil quanto na Argentina. 
Mas onde e como ocorre a formação dos professores universitários, também denominados professores formadores?

Antes de respondermos essa questão, precisamos apresentar uma definição do que seriam os professores formadores. De modo básico, podemos afirmar que estes são todos os profissionais que atuam no Ensino Superior e estão envolvidos no processo de formação de outros professores, seja na formação inicial ou na continuada (cursos de Pós-Graduação lato e stricto sensu e/ou cursos diversos), independentemente de eles serem iniciantes ou não. Quanto aos professores formadores que atuam nos cursos de Graduação, consideramos que não se trata apenas daqueles que trabalham com as disciplinas cujo foco se concentra no eixo pedagógico/didático, mas sim comporta todo o quadro de docentes dos cursos, independentemente da disciplina de atuação. (MIZUKAMI, 2006; VAILLANT, 2010).

Apesar dessa possível definição, concordamos com Gatti et al. (2019, p. 317) que

Caracterizar o ofício de professor formador de professores é bastante complexo, pois ele não está constituído e não tem uma função bem identificada e homogênea. [Sendo necessário] definir uma agenda de estudos sobre o formador: especificidades do seu trabalho docente; caracterização dos formadores e dimensões dos contextos em que trabalham e do seu perfil; formação do formador; concepções de formação predominantes entre os formadores etc. [...].

Ou seja, muitas pesquisas ainda precisam ser realizadas, sob diferentes ângulos, para mapear e caracterizar a profissão do professor formador, assim como os diversos aspectos da sua formação.

Retomando a pergunta anterior, onde e como ocorre a formação do professor formador? Diferentemente da formação do docente que irá atuar na Educação Básica, que ocorre principalmente na Graduação, a formação do professor formador apresenta possibilidades múltiplas, ainda mais quando comparamos Brasil e Argentina. Ou seja, a resposta dessa pergunta exige a compreensão de diversos aspectos, que buscaremos apresentar ao longo deste artigo.

\section{Condições de trabalho, titulação máxima e exigências para atuação no ensino superior}

Quais são as exigências para atuação no Ensino Superior no Brasil e na Argentina? Quais são as condições de trabalhos dos professores universitários nesses dois países? Qual é a titulação máxima exigida para atuar como professor formador nos cursos de Graduação em ambos os países?

Ao analisarmos o aparato legislativo no Brasil e na Argentina, identificamos que há diferenças entre as exigências de titulação máxima para atuação no Ensino 
Superior, assim como as condições de trabalho dos professores formadores nos dois países são distintas.

Na Argentina, o tipo de formação que se exige para atuação no Ensino Superior aparece na Ley de Educación Superior n 24.521, de 7 de agosto de 1995, no art. 36, ao estabelecer que “[...] Os docentes de todas as categorias deverão ter título universitário igual ou superior ao nível no qual exercerá a docência, requisito que só poderá ser ignorado em caráter estritamente excepcional quando se provarem méritos sobressalentes" (ARGENTINA, 1995, livre tradução). Em outras palavras, nesse país não há exigência de que o professor universitário tenha Pós-Graduação lato ou stricto sensu para atuar na Graduação. Ou seja, apenas o curso de Graduação (independentemente da habilitação, Bacharelado ou Licenciatura) já o habilita a atuar como professor formador.

Quanto ao Brasil, as exigências de formação para a atuação no Ensino Superior aparecem na Lei de Diretrizes e Bases da Educação Nacional (LDB) n 9.394/96:

Art. 66. A preparação para o exercício do magistério superior far-se-á em nível de pós-graduação, prioritariamente em programas de mestrado e doutorado.

Parágrafo único. O notório saber, reconhecido por universidade com curso de doutorado em área afim, poderá suprir a exigência de título acadêmico. (BRASIL, 1996, online).

Vemos, portanto, que em nosso país há uma exigência maior de qualificação para atuação no Ensino Superior, todavia, no que se refere às possíveis variações da titulação máxima para os processos seletivos no Ensino Superior em nível nacional, a Lei no 12.863, de 24 de setembro de 2013, estabelece no art. 8, nos joj 1으 e 3ㅇ, que o título de doutor pode ser substituído pelo de mestre, especialista e/ou graduado se houver carência de pessoas com o título de doutor na região.

Tendo por referência as exigências legais de titulação para atuação no Ensino Superior nos dois países, vemos que na Argentina elas são menores do que no Brasil. Entretanto, precisamos questionar se apenas uma Graduação em Arte (que tem por objetivo principal formar o professor para atuar na Educação Básica no caso da Licenciatura ou formar o artista no caso do Bacharelado) ou até mesmo a Pós-Graduação stricto sensu (cujo foco é a pesquisa) é suficiente para a formação do professor formador. A resposta é simples: esses espaços não são/estão aptos integralmente para essa função, embora auxiliem e direcionem parte do processo formativo.

Consideramos, portanto, que

[...] a formação do professor formador ocorre de maneira heterogênea e, na maioria das vezes, por meio de uma autoformação, visto que os professores universitários dos cursos de Licenciatura e dos Professorados podem acessar a docência no Ensino Superior sem necessariamente ter uma formação pedagógica e, muitas vezes, sem ter experiência anterior de Ensino Superior, 
por meio de estágios [...]. Ou seja, muitas vezes ele aprende a formar futuros professores a partir das suas experiências anteriores como docente da Educação Básica, como discente na Graduação, na Pós-Graduação e/ou pelo convívio com outros docentes universitários. (ALVARENGA, 2020, p. 51).

Esse processo autoformativo é plural, assim como apresenta múltiplas possibilidades de pesquisa, de produção artística ou não, de formação institucional/formal, de vivências docentes etc. Como as legislações para atuação no Ensino Superior nos dois países não exigem que os candidatos à docência desse nível tenham formação pedagógica e os cursos de pós-graduação stricto sensu não se encarregam, necessariamente, desse aspecto, embora muitos ofertem estágio no Ensino Superior, muitos professores formadores podem atuar na formação de outros docentes sem terem uma formação pedagógica para tal, o que consideramos prejudicial para o processo educativo.

Quanto à titulação máxima dos professores formadores selecionados (604) que atuam/atuavam nos cursos de Artes Visuais nos dois países, apresentamos a seguir o Gráfico 1 comparativo:

Gráfico 1. Comparação entre a titulação máxima dos professores formadores dos cursos de formação docente em Artes Visuais no Brasil e na Argentina, em \% (2020)

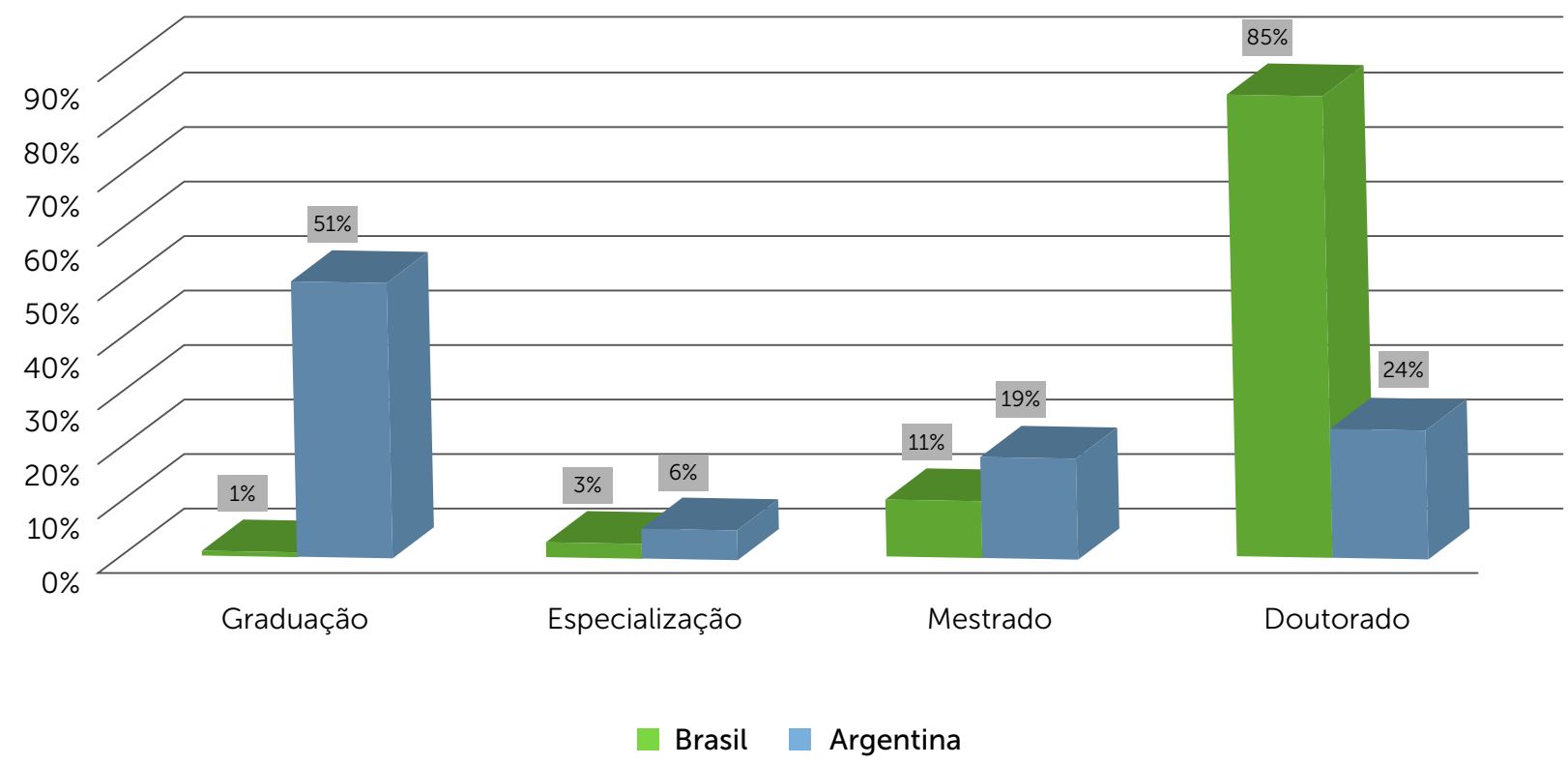

Fonte: Elaborado por Alvarenga (2020, p.296). 
O Gráfico 1 apresenta que, no Brasil, apenas 1\% dos professores formadores selecionados tem graduação, $85 \%$ têm doutorado, $11 \%$ têm mestrado e $3 \%$ especialização como a titulação máxima; na Argentina, mais da metade (51\%) dos professores universitários tem graduação, $24 \%$ têm doutorado, $19 \%$ têm o mestrado e $6 \%$ especialização como titulação máxima. Nesse sentido, podemos inferir que os diferentes percentuais das titulações máximas dos docentes universitários no Brasil e na Argentina podem ser consequência das legislações que definem a necessidade apenas da Graduação para atuar no Ensino Superior, no caso da Argentina, ou a necessidade de Doutorado, no caso do Brasil, embora haja exceções, como vimos anteriormente.

Outro fator que interfere nessa variação da titulação máxima entre os docentes universitários de Arte nos dois países é a criação dos PPGs stricto sensu da área artística, que embora tenham tido sua origem a partir da segunda metade do século $\mathrm{XX}$, o processo de expansão nos dois países foi divergente. Outro elemento refere-se ao "[...] fato de os cursos de Pós-Graduação stricto sensu serem pagos na Argentina, e no Brasil eles são predominantemente gratuitos e ofertados por IES públicas." (ALVARENGA, 2020, p. 373). E, ainda, as diferentes condições de trabalho, as remunerações e os concursos/processos seletivos também estão diretamente associados a essa variação da titulação máxima entre os docentes selecionados nos dois países, como veremos a seguir.

No que se refere às condições de trabalho dos professores formadores que atuam nos cursos de Artes Visuais selecionados, estas coadunam com a situação dos demais professores universitários nos dois países analisados. Na Argentina, há uma hierarquização do trabalho docente:

\footnotetext{
La posición y el compromiso laboral de los docentes dentro de la estructura académica de las universidades nacionales se determinan fundamentalmente por dos variables. En primer lugar, el grado de responsabilidad y el perfil de las tareas a desempeñar dentro de la organización universitaria se delimitan según la categoría del cargo: profesores (titular, asociado, adjunto) y auxiliares docentes (jefe de trabajo práctico, auxiliar de primera, auxiliar de segunda). En segundo lugar, la intensidad de la carga horaria puede ser exclusiva (40 horas semanales), semiexclusiva (20 horas semanales) o simple (10 horas semanales). (FANELLI, 2016, p. 25)
}

Vemos, portanto, que há uma diversidade de funções de acordo com a categoria do cargo, assim como de carga horária de trabalho, todavia, o que chama a atenção na Argentina é o fato de existir a condição dos professores "voluntários", aspecto também conhecido como ad honorem (não recebem remuneração), ou seja, esses professores universitários "[...] podem trabalhar durante vários anos até acumularem um 'antecedente' que os habilitem a disputar alguma das vagas remuneradas, mas sem estabilidade." (SOUZA; PAIVA, 2018, p. 11). Na Argentina, os concursos para atuação no Ensino Superior têm em média seis anos, após esse período o professor precisa realizar um novo processo seletivo. No Brasil, o professor concursado tem estabilidade até se aposentar. 
(CENTENO, 2017). Além disso, ao buscarmos dados gerais sobre a carga horária de trabalho dos professores universitários, englobando diversas áreas do conhecimento, na Argentina, em 2018, encontramos que 67\% dos docentes universitários atuavam no regime de dedicação simples (10 horas semanais), indicando que, para conseguirem uma renda mensal básica, eles precisavam atuar em mais de uma IES ou conciliarem o trabalho de professor formador com algum outro tipo de profissão remunerada. Tais aspectos podem diminuir o vínculo do professor com a IES e com os estudantes. Além disso, Lamarra e Centeno (2011) afirmam que nesse país ter o título de mestre ou de doutor não garante o acesso a maiores/melhores níveis hierárquicos na carreira docente ou a titularidade das cátedras. Ou seja, a titulação não indica perspectivas diferenciadas na carreira universitária.

Quanto à organização e às condições de trabalho dos professores universitários brasileiros, temos o seguinte:

[...] o cargo de professor universitário se organiza em cinco classes, a saber: titular, associado, adjunto, assistente e auxiliar, sendo que esses podem trabalhar tanto com regime de tempo integral (40 horas), com ou sem dedicação exclusiva, como por regime de tempo parcial (geralmente 20 horas), ou ainda como horista (variável). E [...] a legislação estabelece remuneração de acordo com a titulação de modo relacionado com a avaliação por desempenho. [Além disso], os professores universitários que atuam em IES com categoria administrativa pública, em geral, possuem melhores condições de trabalho do que os que atuam em IES privadas. (ALVARENGA, 2021, p. 94-95).

Vemos, portanto, que as condições de trabalho dos professores universitários e as relações de remuneração associadas à maior ou menor titulação em ambos os países são divergentes, sendo mais precárias na Argentina do que no Brasil.

Na sequência, apresentaremos mais detalhes relativos as IES que fizeram parte da pesquisa e como foi o processo de seleção dos professores formadores.

\section{Universo da pesquisa: IES e professores universitários de artes visuais}

Mapeamos os cursos de Graduação e Pós-Graduação ${ }^{3}$ na área de Arte nos dois países e, posteriormente, selecionamos 23 IES públicas que ofertam cursos de Graduação em Artes Visuais na modalidade presencial. Destas, 13 estão localizadas no Brasil: Universidade Federal de Roraima (UFRR), Universidade Federal do Amazonas (UFAM), Universidade Federal do Pernambuco (UFPE), Universidade Federal do Maranhão (UFMA), Universidade Federal do Mato Grosso do Sul (UFMS), Universidade Federal de Goiás (UFG), Universidade Federal do Espírito Santo (UFES), Universidade

3 Para verificar os detalhes da quantidade de cursos de Graduação e Pós-Graduação da área de Arte, localização, modalidades, habilitações, linhas de pesquisa etc. no Brasil e na Argentina, recomendamos a leitura da tese da autora. 
Federal de Uberlândia (UFU), Universidade de São Paulo (USP), Universidade Estadual do Rio de Janeiro (UERJ), Universidade Federal de Paraná (UFPR), Universidade Estadual de Santa Catarina (UDESC) e Universidade Federal de Rio Grande do Sul (UFRGS). Na Argentina, selecionamos apenas as IES universitárias que ofertavam o curso de formação docente em Artes Visuais e/ou nomenclaturas correlatas, sendo um total de 10: Universidad Nacional de Cuyo (UNCUYO), Universidad Nacional de las Artes (UNA), Universidad Nacional de Córdoba (UNC), Universidad Nacional de La Plata (UNLP), Universidad Nacional de Rosario (UNR), Universidad Nacional de Misiones (UNAM), Universidad Nacional de San Juan (UNSJ), Universidad Autónoma de Entre Ríos (UADER), Instituto Universitario Patagónico de las Artes (IUPA) e Universidad de Buenos Aires (UBA). A localização dessas instituições pode ser visualizada nas Figuras 1 e 2, respectivamente.

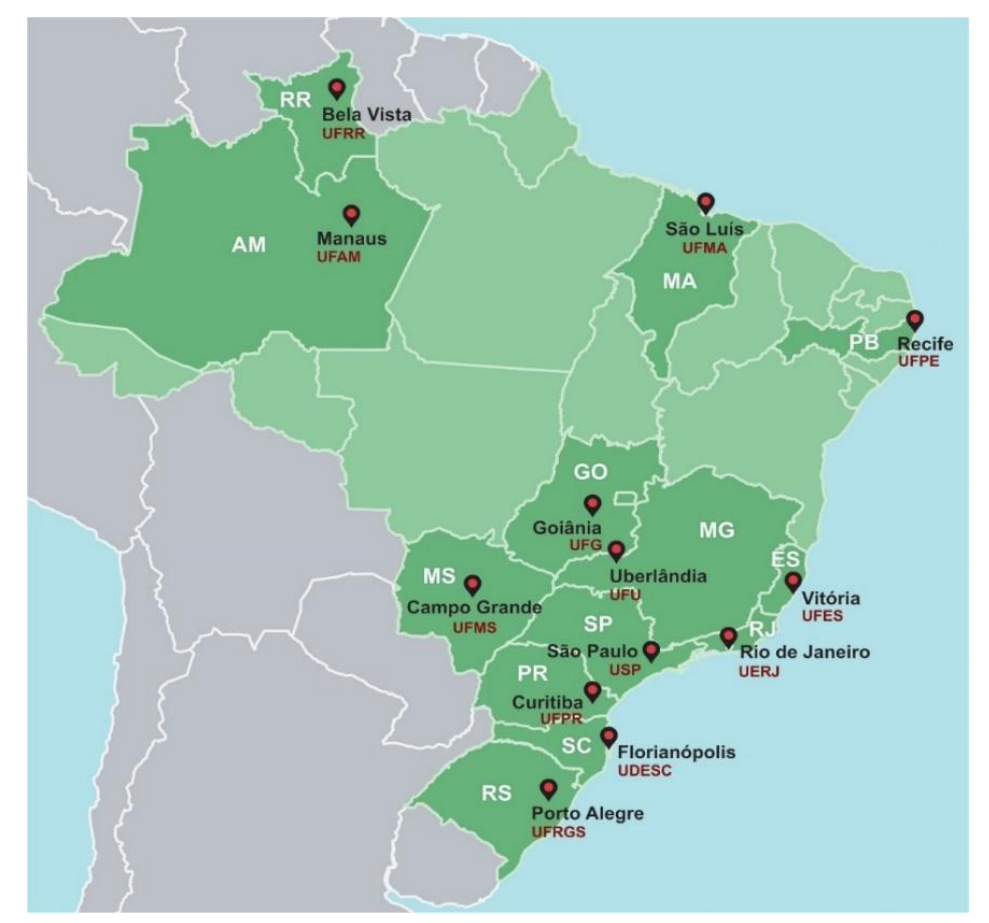

Figura 1. Mapa do Brasil com a localização dos cursos selecionados para coleta de dados sobre os professores formadores de Artes Visuais

Fonte: Elaborada por Alvarenga (2020, p. 263).

A Figura 1 mostra que as IES selecionadas estão localizadas nas cinco regiões brasileiras, justamente para contemplar uma maior diversidade territorial, visto que a maior concentração dos cursos de Licenciatura em Artes Visuais, segundo estudos recentes do OFPEA/BRARG, está nas regiões Sul e Sudeste. No que se refere à quantidade de professores formadores selecionados por IES, apresentamos a Tabela 1 a seguir: 
Tabela 1. Quantidade de professores formadores selecionados nos cursos de Artes Visuais, por IES, no Brasil

\begin{tabular}{|c|c|c|c|c|c|c|c|c|c|c|c|c|c|}
\hline IES & UFPR & UDESC & UFRGS & UFRR & UFAM & UFPE & UFMA & UFMS & UFG & UFES & UFU & UERJ & USP \\
\hline $\begin{array}{l}\text { № de } \\
\text { profs. }\end{array}$ & 13 & 27 & 30 & 11 & 13 & 16 & 16 & 14 & 18 & 54 & 26 & 24 & 18 \\
\hline
\end{tabular}

Fonte: Elaborada pela autora com base em Alvarenga (2020).

No total, 280 professores universitários foram selecionados. Quanto às possíveis explicações para a diversidade da quantidade deles por IES, precisamos considerar que:

1) os professores dos cursos de Artes Visuais são de departamentos distintos, por exemplo: Departamento de Educação, Departamento de Teoria e História, Departamento de Arte etc. Muitas vezes, o site da IES apresentava os nomes apenas dos docentes do departamento específico de Arte e até mesmo no horário das disciplinas aparecia o nome do departamento onde a disciplina era ofertada, mas não aparecia o nome do professor que lecionaria a disciplina [...]; 2) se a IES apresenta PPGs stricto sensu ou não. No primeiro caso, os docentes costumam lecionar em menos disciplinas na Graduação, o que faz com que haja mais docentes no curso, já no segundo caso o mesmo docente assume várias disciplinas para fechar a carga horária de trabalho, principalmente os substitutos; 3 ) algumas IES não apresentaram os nomes dos docentes que estavam atuando como substitutos, inserindo apenas os dos efetivos. (ALVARENGA, 2020, p. 265).

Vale ressaltar que esse conjunto de fatores também explica a diversidade da quantidade de professores formadores encontrados nas IES da Argentina. Na sequência, apresentaremos a localidade das IES selecionadas nesse país (Figura 2) e a quantidade de professores formadores que foram selecionados (Tabela 2). 


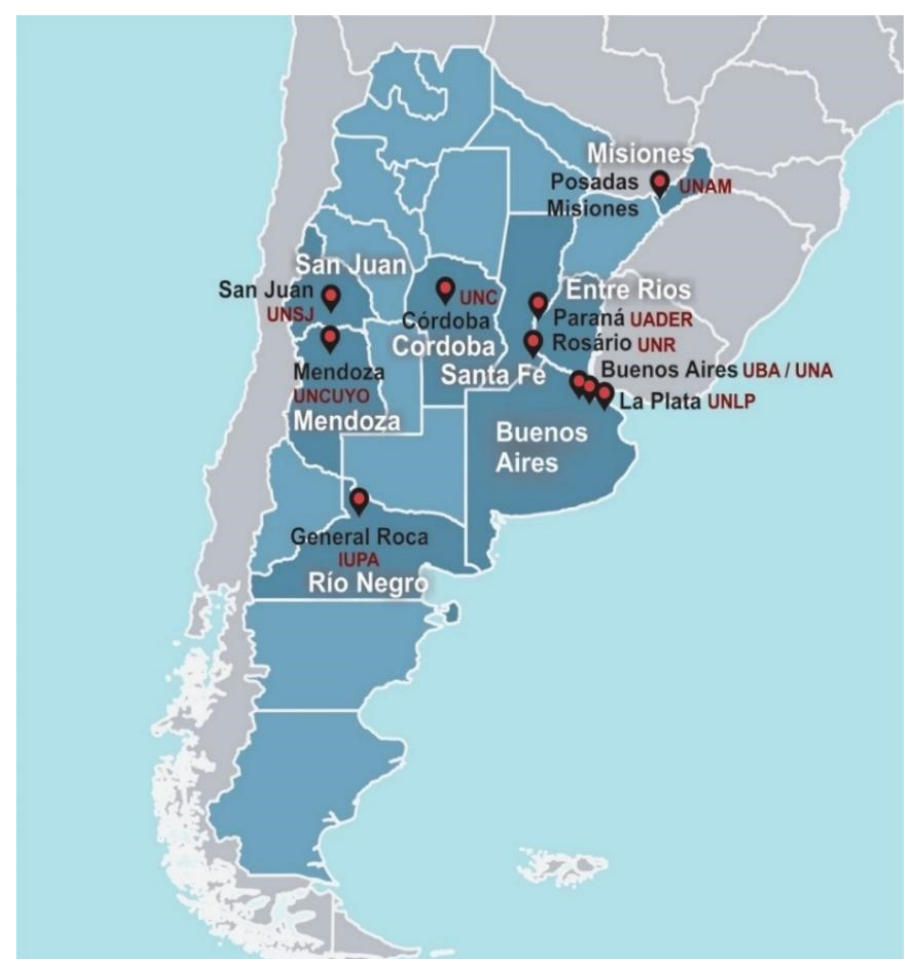

Figura 2. Mapa da Argentina com a localização dos cursos selecionados para coleta de dados sobre os professores formadores de Artes Visuais

Fonte: Elaborada por Alvarenga (2020, p. 261).

Tal como no Brasil, podemos observar, na Figura 2, a localização das IES selecionadas na Argentina.

Na Argentina, os cursos de Professorados [formação docente] são ofertados por IES universitárias e não universitárias (terciárias), sendo que as primeiras realmente contam com uma estrutura de universidade e uma maior autonomia docente, já as segundas não. (ALVARENGA, 2020, p. 40).

Assim, as instituições naquele país abrangem uma diversidade de províncias e algumas estão mais concentradas em determinadas regiões, geralmente capitais e/ ou grandes centros urbanos. Na Tabela 2, apresentamos a quantidade de professores selecionados em cada uma das IES: 
Tabela 2. Quantidade de professores formadores selecionados nos cursos de Artes Visuais e/ou com nomenclaturas similares por IES na Argentina

\begin{tabular}{|c|c|c|c|c|c|c|c|c|c|c|}
\hline IES & UNCUYO & UNA & UNC & UNLP & UNR & UNAM & UNSJ & UNSJ & IUPA & UBA \\
\hline $\begin{array}{c}\text { № de } \\
\text { profs. }\end{array}$ & 12 & 93 & 40 & 34 & 31 & 24 & 17 & 9 & 9 & 55 \\
\hline
\end{tabular}

Fonte: Elaborada pela autora com base em Alvarenga (2020).

Após a seleção das IES, acessamos as matrizes curriculares, os quadros de horários das disciplinas e seus respectivos docentes e/ou o próprio quadro de professores apresentados pelos sites dos cursos de Artes Visuais.

Para encontrarmos possiveis tendências de formação dos professores formadores, fizemos a análise dos currículos (trajetória acadêmica institucional), buscando identificar as habilitações (Licenciatura ou Bacharelado), as áreas da formação inicial e continuada, assim como a presença/ausência de produção artística dos docentes selecionados. Os resultados podem ser vistos na sequência.

\section{Tendências da formação dos professores formadores que atuam nos cursos de artes visuais (Brasil e Argentina)}

Para encontrarmos as tendências de formação dos professores formadores que atuam nos cursos de Artes Visuais no Brasil e na Argentina, após a seleção dos docentes, analisamos seus currículos para identificar suas áreas de formação inicial e continuada, de acordo com os eixos disciplinares de atuação supracitados. De acordo com Fonseca da Silva (2014), tais eixos comportam um conjunto de disciplinas que apresentam características comuns de conteúdo e de direcionamento das atividades. "Embora todas as disciplinas do currículo dos cursos possam contemplar em maior ou menor grau todos esses eixos, há predominância de direcionamentos entre as disciplinas." (ALVARENGA, 2020, p. 302). Tendo por referência as matrizes curriculares das 23 IES selecionadas, no Quadro 1 apresentamos algumas disciplinas que se encaixam nesses diferentes eixos: 
Quadro 1. Divisão das disciplinas dos cursos de formação docente em Artes Visuais por eixos disciplinares

\begin{tabular}{|c|c|c|}
\hline Teórico/histórico & Artístico/ateliê & Pedagógico/ensino \\
\hline $\begin{array}{l}\text { História da Arte; Semiótica; } \\
\text { Filosofia da Arte; } \\
\text { Antropologia da Arte; Leitura } \\
\text { de Imagem; Sociologia da } \\
\text { Arte; Crítica de Arte; Estética; } \\
\text { Museologia; Semiologia e } \\
\text { Retórica Visual; Introdução à } \\
\text { Curadoria e Mediação; etc. }\end{array}$ & $\begin{array}{l}\text { Pintura; Escultura; Gravura; } \\
\text { Desenho; Fotografia; Taller } \\
\text { de Produção Artística; } \\
\text { Audiovisual; Fotografia e } \\
\text { Cinema; Ferramentas Digitais; } \\
\text { Poéticas Contemporâneas; } \\
\text { Arte de Ação (happenings, } \\
\text { performances etc.); etc. }\end{array}$ & $\begin{array}{l}\text { Metodologia do Ensino de } \\
\text { Arte; Estágio Supervisionado/ } \\
\text { Residência Docente; } \\
\text { Prática de Ensino; Didática; } \\
\text { Psicologia da Educação; } \\
\text { Taller de Ação Educativa; } \\
\text { Gestão e Organização } \\
\text { do Trabalho Pedagógico; } \\
\text { Políticas Públicas } \\
\text { Educacionais; etc. }\end{array}$ \\
\hline
\end{tabular}

Fonte: Elaborado por Alvarenga (2020, p. 303) e adaptado pela autora.

Tendo por base esses eixos disciplinares de atuação, analisamos os currículos dos professores formadores selecionados nos dois países utilizando a Plataforma Lattes no Brasil e o sistema de currículo Cvar do Sistema de Información de Ciencia y Tecnología Argentino (SICYTAR), entre outros sites, para acessarmos os currículos dos professores da Argentina. Encontramos tendências de formação no que se refere às áreas do conhecimento dos cursos da Graduação e Pós-Graduação, habilitações, se fizeram parte ou toda a formação na mesma IES que atuam como docentes, assim como se têm ou não produção artística. Na Figura 3, podemos observar a síntese das tendências encontradas: 


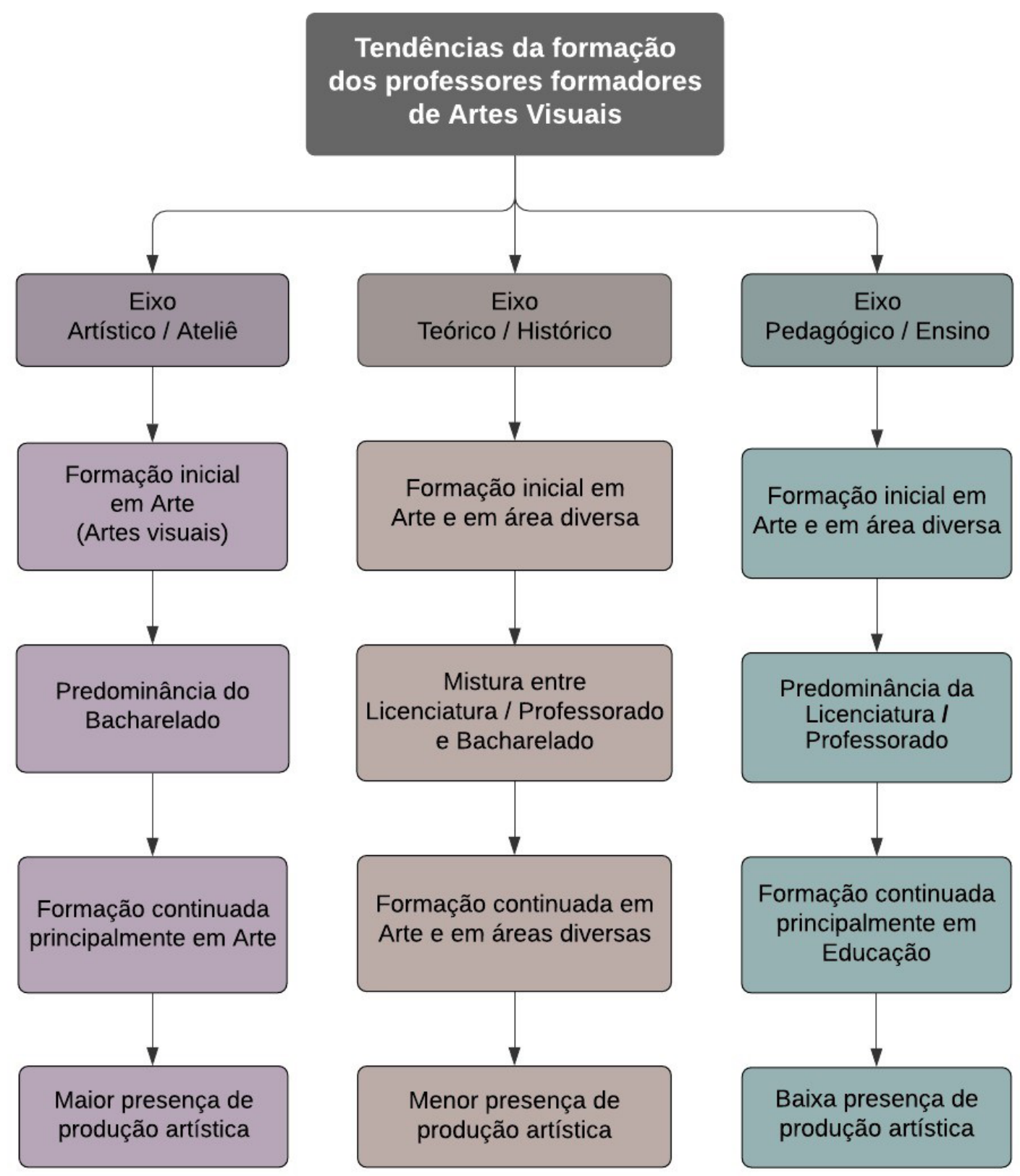

Figura 3. Síntese das tendências de formação e de produção artística dos professores formadores de Artes Visuais no Brasil e na Argentina

Fonte: Elaborada por Alvarenga (2020, p. 379).

A partir da Figura 3, podemos observar que os professores que atuam em cada um dos eixos disciplinares têm formações diferenciadas no que se refere às áreas da Graduação e Pós-Graduação stricto sensu, assim como a presença ou não de produção artística. No eixo artístico/ateliê, vemos que há uma predominância da formação inicial dos professores universitários em Artes Visuais, com a habilitação Bacharela- 
do, assim como a Pós-Graduação stricto sensu também na área de Arte. Nesse eixo, mais professores atuam como artistas. Quanto ao eixo teórico/histórico, a formação inicial e continuada dos professores selecionados ocorre tanto em Arte quanto em área diversa (mista), sendo as mais comuns História, Filosofia, Letras, Direito etc., e as habilitações dos cursos de Graduação são tanto na Licenciatura quanto no Bacharelado. Nesse eixo, detectamos uma quantidade menor de produção artística, embora, a partir dos currículos dos professores, constatamos que muitos atuam como curadores, críticos de arte e escrevem livros e artigos relacionados à História da Arte. Já no eixo pedagógico/ensino, a formação inicial também é mista, sendo a Licenciatura a habilitação predominante. Quanto à Pós-Graduação stricto sensu, a maior parte realizou essa formação na área de Educação. Cabe ressaltar, ainda, que, nesse eixo, a maioria dos professores não tem produção artística.

Outro dado que encontramos relativo à formação dos professores formadores de Arte refere-se ao fato de a maior parte dos professores terem feito toda ou parte da formação (Graduação e/ou a Pós-Graduação) na mesma IES em que atuam como docentes: "[...] Na Argentina, 77\% dos professores formadores atuam na mesma IES em que se formaram (seja na Graduação ou na Pós-Graduação ou em ambas); no Brasil, 59\%." (ALVARENGA, 2020, p. 371). Esse dado indica que as universidades, baseadas no modelo de produção e reprodução de um capital científico, ao mesmo tempo que permite a criação e a produção de novos valores "reaproveita" os discentes.

Identificamos, ainda, que mais de dois terços dos professores universitários selecionados nos dois países não atuam como artistas de modo formal e que "[...] a maior concentração de produção artística dos professores formadores ocorre entre os que atuam em disciplinas do eixo artístico/ateliê, sendo $79 \%$ no Brasil e $92 \%$ na Argentina. [Ou seja, eles atuam] em disciplinas de cunho "prático" (desenho, pintura, escultura etc.)". (ALVARENGA, 2020, p. 382).

Vimos, ainda, que há uma predominância do Bacharelado na formação desses docentes. Consideramos que esses dois aspectos contribuem para a maior produção artística dos docentes desse eixo.

Quanto à produção artística encontrada, constatamos que

1) havia tanto regularidade quanto ausência de longos períodos; 2) produções artísticas recentes em contraposição a décadas de produção científico-acadêmica; 3) variação dos tipos de trabalhos produzidos (mais conceituais/ contemporâneos e mais tradicionais). (ALVARENGA, 2020, p. 382).

Sobre essa variação, consideramos que as demandas do "[...] trabalho universitário, a maior valorização da produção científica/acadêmica, assim como o tempo com os alunos pode ter afetado essa continuidade. [...] assim como o excesso de "funções" dos professores formadores, associadas à gestão e/ou a aspectos administrativos." (ALVARENGA, 2020, p. 382). 
A partir dos resultados encontrados, perguntamos: o que pode ter motivado essas tendências de formação e de produção artística ou não entre os professores formadores de Artes Visuais nos dois países? Podemos inferir que elas dependem de diversos fatores que ultrapassam possíveis elementos subjetivos, tais como as próprias características das disciplinas de atuação dos professores formadores podem motivar a formação continuada no que se refere a temas/áreas de estudo, assim como maior motivação para a produção artística ou não. Outros elementos que perpassam por essas tendências de formação podem estar relacionados com a oferta ou não de habilitações (Licenciatura e/ou Bacharelado) nos cursos de Graduação, localização e criação/expansão dos cursos de Pós-Graduação stricto sensu na área de Arte, e mais especificamente de Artes Visuais, distribuição regional desses cursos, entre muitos outros fatores que carecem de mais investigações.

\section{Considerações finais}

A partir do exposto, identificamos que há poucas pesquisas sobre a formação dos professores formadores, tanto na América Latina quanto no Brasil e na Argentina, em especial os de Artes Visuais, e que aqueles são responsáveis pelo processo formativo de outros docentes, seja na formação inicial, seja na continuada, e, em geral, atuam como professores universitários. Retomando a pergunta inicial: onde e como ocorre a formação dos professores formadores? Vemos que há múltiplas respostas, podendo ser de acordo com o aparato legal do sistema educativo de cada país, as condições de trabalho, as exigências e/ou retornos de uma maior titulação, entre outros aspectos que ultrapassam elementos subjetivos. Para além do aspecto institucional/formal, também ocorre um processo autoformativo, visto que apenas a Graduação e/ou a Pós-Graduação, ou mesmo ambas, não são suficientes para a formação nesse nível de ensino.

No que se refere à titulação máxima e às exigências para atuação no Ensino Superior nos dois países selecionados, vimos que há diferenças relativas às exigências legais para tal no que tange à titulação máxima exigida. Na Argentina, apenas com a Graduação já é possível ser professor universitário, e no Brasil há a exigência do Doutorado, embora haja exceções. Tais normas legais coincidem com os dados encontrados relativos à titulação dos professores de Artes Visuais selecionados, pois na Argentina mais da metade dos docentes tem a Graduação como titulação máxima, e no Brasil a maioria dos professores formadores tem o Doutorado. Vimos, ainda, que as condições de trabalho dos professores universitários na Argentina são mais precárias do que as dos docentes que atuam no mesmo nível no Brasil. Tais dados coincidem, por sua vez, com as demais áreas do conhecimento dos professores universitários em ambos os países. 
Por fim, no que se refere às tendências da formação dos professores formadores dos cursos de Artes Visuais no Brasil e na Argentina, encontramos pontos dissonantes e consonantes. Os aspectos semelhantes se referem às tendências de formação inicial e continuada (habilitações e áreas dos cursos) nos três eixos disciplinares de atuação dos professores formadores dos cursos de Artes Visuais. Dois terços dos professores selecionados não atuam como artistas, sendo que a maior parte dos que têm produção artística formal atua no eixo artístico/ateliê. No que tange às diferenças, vimos que elas englobam elementos externos (legislações, condições de trabalho etc.) que perpassam pela formação/atuação docente no Ensino Superior das demais áreas do conhecimento e não são exclusivas da área de Arte. 


\section{Referências}

\section{ALVARENGA, V. M. A formação dos professores formadores nos cursos de} graduação em Artes Visuais: estudos comparados entre Brasil e Argentina. 2020. Tese (Doutorado em Artes) - UDESC, Florianópolis, 2020.

ALVARENGA, V. M. A formação/atuação dos professores universitários no Brasil e na Argentina: titulações e condições de trabalho. In: SENHORAS, E. (org.). Políticas públicas na educação e a construção do pacto social e da sociabilidade humana. Ponta Grossa: Atena, 2021.

ARGENTINA. Ley de Educacionais Superior no 24.521, del 20 de julho de 1995. Buenos Aires, 1995. Disponível em: http://servicios.infoleg.gob.ar/infoleglnternet/ anexos/25000-29999/25394/texact.htm. Acesso em: 3 abr. 2021.

BRASIL. Lei no 9.394, de 20 de dezembro de 1996. Estabelece as diretrizes e bases da educação nacional. Brasília: Presidência da República, [2009]. Disponível em: http://www.planalto.gov.br/ccivil_03/leis/19394.htm. Acesso em: 29 abr. 2021.

BRASIL. Lei no 12.863, de 24 de setembro de 2013. Altera a Lei no 12.772, de 28 de dezembro de 2012, que dispõe sobre a estruturação do Plano de Carreiras e Cargos de Magistério Federal [...]. Brasília: Presidência da República, 2013. Disponível em: http://www.planalto.gov.br/ccivil_03/_ato2011-2014/2013/Lei/ L12863.htm\#art1. Acesso em: 12 mar. 2021.

CENTENO, C. P. El estudio de la profesión académica universitaria en Argentina. Estado de situación y perspectivas. Integración y Conocimiento, Córdoba, n. 7, v. 2, p. 226-255, 2017.

FANELLI, A. G. Informe nacional: Argentina. Buenos Aires, mar. 2016. Disponível em: https://cinda.cl/wp-content/uploads/2019/01/educacion-superior-en-iberoamericainforme-2016-informe-nacional-argentina.pdf. Acesso em: 6 jan. 2020.

FONSECA DA SILVA, M. C. R. Formação de professores nas Licenciaturas em Artes Visuais: o processo de criação. In: ENCONTRO DA ANPAP, 23., 2014, Belo Horizonte. Anais [...]. Belo Horizonte: UFMG, 2014.

FONSECA DA SILVA, M. C. R.; BUJÁN, F. Políticas públicas de formação docente em artes: perspectivas em duas realidades, Brasil e Argentina. Revista GEARTE, Porto Alegre, v. 3, n. 1, p. 26-52, jan./abr. 2016. 
GATTI, B. A. et al. (org.). Professores do Brasil: novos cenários de formação.

Brasília: UNESCO, 2019.

LAMARRA, N. F.; CENTENO, C. P. La profesión académica universitaria en América Latina, en perspectiva comparada. Educação, Santa Maria, v. 36, n. 3, p. 351-364, set./dez. 2011.

MIZUKAMI, M. G. N. Aprendizagem da docência: professores formadores. Revista e-Curriculum, São Paulo, v. 1, n. 1, [s/p], jul. 2006.

RIZZI, M. C. S. L. Observatório da formação de professores no âmbito do ensino de Arte. In: SEMINÁRIO CAPIXABA SOBRE ENSINO DE ARTE, 10.; ENCONTRO DAS LICENCIATURAS EM ARTES VISUAIS, 2., 2013, Vitória. Palestra. Vitória: UFES, 2013.

SOUZA, C. B.; PAIVA, L. R. B. Elementos comparativos entre o sindicalismo docente universitário da Argentina, Brasil, Colômbia e México, e a contrarreforma universitária neoliberal. In: CONFERÊNCIA INTERNACIONAL GREVES E CONFLITOS SOCIAIS, 4., 2018, São Paulo. Anais [...]. São Paulo: USP, 2018.

TEUBER, M. Relações entre ensino, práticas artísticas e pesquisa: princípios didáticos para a formação do professor de Artes Visuais. 2016. Tese (Doutorado em Educação) - UFPR, Curitiba, 2016.

VAILLANT, D. Formação de formadores. In: ENCONTRO DE FORMAÇÃO DE PROFESSORES DE LÍNGUA INGLESA, 7., 2010, Londrina. Anais [...]. Londrina: UEL, 2010.

Submetido em 25/09/2021.

Aprovado em 09/11/2021. 